\title{
Despertar y encauzar con intención el gusto por la lectura y la escritura. Un imperativo de toda docencia
}

\section{Porfirio Morán Oviedo}

Instituto de Investigaciones sobre la Universidad y la Educación de la UNAM

\section{Resumen}

n el Tercer Estudio Regional $\checkmark$ Comparativo y Explicativo de la Unesco, del 4 de diciembre de 2014, se da a conocer el desempeño de los alumnos de tercero y sexto grado de primaria en matemáticas y lectura de 15 países de América Latina, incluido México; en él se confirman una vez más los reportes de años anteriores. Este estudio de 2014 busca identificar el desempeño de los sistemas educativos de la región, donde Cuba ha destacado reiteradamente por sobre los demás países, mientras que México se ubicó en la quinta posición, detrás de Chile, Brasil, Uruguay y Costa Rica. Por otra parte, de acuerdo con resultados dados a conocer en 2008, en México sólo el 24\% de los alumnos de sexto grado alcanzaron el más alto nivel de desempeño en lectura, mientras que los de tercer grado sólo 16\% lo logra-
Leer y escribir es ejercitar la razón, poner en marcha el pensamiento o como dijera Sealtiel Alatriste, es "hacer aerobics con las neuronas".

Pablo Latapí

ron, frente a Cuba que alcanzó el 54\% (La Jornada, diciembre de 2014).

Estos resultados que reporta la UnESCO, me sirven como punto de partida para darle sustento a una experiencia docente, la cual relacioné con uno de mis proyectos de investigación que realizo en la UNAM, en la que se identificó la problemática de la lectura y escritura, y con una estrategia didáctica apropiada se promovió su mejora con estudiantes de un Taller de Didáctica de la Carrera de Pedagogía de la Facultad de Filosofía y Letras y un grupo de alumnos de la materia de Práctica Docente I y II de la Maestría en Docencia para la Educación Media Superior, ambos espacios académicos de la Unam. En dicha actividad se llevaron a cabo ejercicios deliberados de lectura y escritura y se recogieron evidencias a través de la elaboración de un portafolio del estudiante durante dos semestres de 2013. 
Esta experiencia de práctica docente sirve de referencia y apoyo al presente escrito sobre el problema de la lectura y la escritura; así como para esbozar una propuesta pedagógica donde se aborda esta apremiante problemática en nuestro bachillerato.

\section{Introducción}

Desde hace mucho tiempo la lectura y la escritura han dejado de ser preocupación sustantiva de autoridades educativas, de educadores, de padres de familia y de medios de comunicación. Salvado el escollo de la alfabetización formal, leer y escribir ha quedado como herramienta para sortear tareas escolares y libros de texto. En el caso de los libros, en educación básica éstos caen principalmente en la categoría de los que inculcan conceptos socialmente aceptables como el amor a la patria, los héroes, la bandera, el sistema, los gobernantes y la familia, y en las etapas que siguen (bachillerato y profesional), en las que se enseñan las bases para aprender los oficios o profesiones que conduzcan de la manera más segura y rápida a escalar las alturas del poder adquisitivo y la influencia. Leer $y$ escribir por el placer de imaginar, de explorar, de evocar, de enriquecer el acervo y la capacidad intelectual, casi no existe en los planes de estudio ni en la práctica docente a ningún nivel, y enseñar a leer con sentido pedagógico, histórico y reflexivo para desarrollar la capacidad crítica que define al adulto autónomo, menos aún (Page, 1993).

Los que no leen, por el tremendo esfuerzo que les cuesta, se privan de toda posibilidad de gozar y apreciar el poder inherente en la lectura y la escritura y poco se preocupan de que sus hijos adquieran esa satisfacción, además poco pueden enseñar a sus alumnos de la necesidad vital de adquirirla. Perpetúan estados de ignorancia, de dependencia y frustración evidentes desde hace ya muchas generaciones en Latinoamérica.

Este enorme vacío comienza en casa, se extiende a la escuela primaria y se hace cada vez más ancho y profundo con el paso de los años escolares. En el bachillerato, donde por primera vez la oferta y la extensión de las selecciones presentadas, todavía en su mayoría en forma de textos con requerimiento académico, se hace más variada, abriendo apenas un resquicio sobre las vastas posibilidades de la lectura y escritura, para entonces el daño personal ya es tan grande que pocos lo superan y llegan a ser buenos lectores y mucho menos para llegar a ser lectores embelesados y ávidos. El simple ingreso o paso por la universidad del pequeño porcentaje de la población que hasta ahí llega, hoy no garantiza nada, gracias a la terrible desvirtuación pedagógica y didáctica que sufren muchas de las instituciones educativas que ostentan, sin merecerlo, ese título.

Aprisionados por unos medios de comunicación - sobre todo por la televisión-y una escuela que desde la enseñanza primaria, subestima la capacidad del educando para aprender, lo circunscribe a lo que alguna vez se determinó era congruente con su entorno, y en el otro extremo están la preparatoria y la universidad, que se supone les preparará para desempeñarse exitosamente en determinado mercado de trabajo, el estudiante avanza y sale sin lectura, 
sin horizontes, sin atributos, sin recursos para enfrentar con solvencia exigencias básicas de su vida personal, académica y profesional.

Hace tiempo que no se educa sino que se entrena, se adiestra. La presión de la iniciativa privada con su visión tecnocrática sobre la educación a través de las instituciones que sostiene y promueve, solo ha venido a exacerbar una tendencia creciente desde los años cincuenta, de ofrecer y cursar en las universidades carreras especializadas que limitan y truncan la formación crítica, a veces atrofian la capacidad intelectual, encaminando al estudiante hacia el ejercicio de tal o cual profesión o actividad laboral cuya única finalidad es el beneficio personal, el poder y la influencia, aunque a la larga tenga que conformarse con lo que el mercado ofrezca. Para esas actividades no se necesita leer más que manuales y reportes técnicos, la no lectura auspiciada desde la enseñanza primaria.

La lectura y escritura en todos los ámbitos, inculcada como actividades importantes y valiosas desde los primeros años por maestras/os que son lectores ellos mismos y tienen lectura que compartir, puede contrarrestar la tendencia de entrenar al escolar para ser obrero calificado o ejecutivo de medio nivel al servicio de la inversión extranjera o nacional. Solo la lectura educará a todos los ciudadanos y hará a todos partícipes plenos y críticos en la comprensión y dirigencia de su país.

Hasta mediados del siglo pasado esas humanidades y ciencias sociales eran la patente de una persona educada; el fundamento de una inteligencia desarrollada a la luz de la ética y la lógica, capaz de asumir responsabilidades y cumplirlas en beneficio de sí y de otros, fueran ciudadanos accionistas, clientes, amigos, alumnos, hijos, familiares, sin anteponerles otra preocupación de índole egoísta que el orgullo de haberlas desquitado cabal y honrosamente.

Desde esas fechas han venido perdiendo terreno dentro y fuera de la enseñanza media superior y superior ante los atractivos de las especialidades de moda: la economía para entrar a la alta burocracia, la administración de empresas para escalar las cumbres de la empresa privada, la medicina institucionalizada, también para el sector privado, más todas las tecnologías y ciencias aplicadas que alimentan esas empresas; incluso el derecho con sus múltiples especialidades.

Esas especializaciones obviamente no están viciadas en sí, ni vician a sus practicantes. Son sus aplicaciones por mujeres y hombres privados de lectura (y que las devalúan por falta de conocimiento) las que destrozan el planeta y enferman y matan a sus habitantes. Ya son contadas las industrias cuyos productos no tienen algún efecto nocivo sobre el consumidor, el usuario o el ambiente, dado que en la persecución de la máxima ganancia, absolutamente todo vale.

Mejor harían tanto gobierno como iniciativa privada en dar la espalda a abusos y distorsiones de los tecnócratas y volver a buscar sus cuadros entre los egresados en humanidades y ciencias sociales. Estos por lo menos tendrían una sana dosis de escepticismo y sentido histórico adquirida en sus lecturas, como para tal vez querer 
promover que el país emule lo mejor de las grandes tradiciones culturales de la humanidad, no solo el consumismo, el desplante y la arrogancia en la utilización del conocimiento.

Abandonar el caos de la ciencia social para volver a la lectura de la historia sin haber enseñado a leer y escribir desde una perspectiva histórica, literaria y con sentido crítico, comprometerá a varias generaciones de alumnos. Pero si ahora mismo se empieza a enseñar a leer y escribir con ese criterio desde la enseñanza primaria y se retoma con sentido propedéutico en los siguientes niveles educativos, no hay la menor duda de que en la siguiente generación se verá la diferencia. Esto parece distante, pero en la tarea educativa los cambios de fondo no se operan de la noche a la mañana. Sí se puede preparar alumnos para leer y gozar la lectura de la gran tradición cultural de la humanidad y a través de ella crear ciudadanos capaces de enriquecer y proteger el planeta y sus especies, su entorno, sus congéneres y a sí mismos.

Como se puede observar, el tema y problema que nos ocupa es grave y de viejo cuño, por eso en este trabajo no tenemos grandes pretensiones, porque no es un objeto de estudio al que me haya dedicado durante mi trayectoria académica, pero a raíz de mi incorporación como profesor y tutor de la MADEMS, sobre todo en mi relación con los alumnos-maestros del Campo de Español, percibo de manera más clara la importancia y la necesidad de fomentar en los alumnos-maestros la enseñanza y el aprendizaje de la lectura y escritura como herramienta básica para mejorar su formación como docentes de Bachillerato.
En el presente artículo se hace una revisión general de la situación de la lectura y escritura en nuestra realidad escolar, se problematiza acerca de su importancia y trascendencia para la formación y el desarrollo personal, académico y profesional de los alumnos; se realiza un asomo breve a sus orígenes, desde la enseñanza básica y su recurrencia en los demás niveles educativos, se destaca el papel relevante que juega la didáctica, en cuanto teoría y práctica de la enseñanza, para el mejor aprendizaje de la lectura y la escritura y, finalmente, se vislumbra una estrategia pedagógica para enfrentarla en los procesos de enseñanza y aprendizaje.

\section{Indicios sobre el origen del problema de la lectura y la escritura}

Desde un inicio la enseñanza de la ortografía - y la lectura y la escritura en general- ha consistido en estudiar la normativa, analizar palabras difíciles que pueden resultar ambiguas y mostrar el uso acertado de los signos de puntuación, muchos cuadernos para instruir en el arte de escribir correctamente (antiguos y presentes) se centran en estos aspectos, de igual manera, los errores en este campo - en su mayoría- comúnmente se han adjudicado a fallos de transcripción fonética, desconocimiento de las reglas y confusiones con homónimos y homófonos; sin embargo, como se ha tratado de bosquejar a lo largo de este escrito-investigación, los problemas en ortografía no versan ya únicamente sobre estos temas, por ello actualmente la principal preocupación radica en que se ha viciado la codificación básica de la escritura, produciendo un lenguaje simplificado, se- 
mejante al utilizado en espacios virtuales. Profesores de todos los niveles académicos denuncian esta tendencia entre los jóvenes y manifiestan inconformidad al tener que auxiliar en la recuperación de este conocimiento, pues, aparentemente, ya había sido dominado desde la enseñanza básica.

En la exploración de alternativas que brinden auxilio a esta problemática se pueden hallar infinidad de manuales con decenas de ejercicios didácticos para el aprendizaje y recuperación de la lectura y la escritura, desde aquellos tradicionales con actividades basadas en copiar textos, practicar el dictado y trabajar la dicción, hasta los más alternativos que proponen juegos extravagantes como memoramas, ocas, crucigramas, sopas de letras, etc. Según los expertos todos estos recursos tienen valía y cierto grado de éxito, especialmente si se explotan dentro de estrategias didácticas donde se combinen dichos ejercicios, no obstante, ellos mismos reconocen, que no existe un método que garantice completamente el aprendizaje de la destreza de la lectura y la escritura, y menos aún en las escuelas donde no se ha querido o no se ha entendido esta trascendente necesidad de los seres humanos.

Tal como se mencionó en líneas anteriores, la práctica de la lectura y la escritura dentro de las instituciones educativas, aunque se considera un recurso básico y cotidiano presente en todas las disciplinas y áreas de estudio, no ocupa un interés verdadero dentro del currículo y en el espacio del aula, es decir, no cuenta con fundamentos teóricos que respalden una metodología establecida, y, por tanto, cuando se presentan fenómenos como descuido, deficiencias y errores en la lectura y la escritura, los profesores carecen de formación psicopedagógica y estrategias didácticas apropiadas para intervenir adecuadamente. Es decir, en las prácticas docentes se planea y realiza una educación - en este caso de lectura y escritura - sin pedagogía (Latapí, 1998).

Esta escasez de opciones dentro de las aulas de educación primaria, secundaria y bachillerato - población en la que interesa incidir, aunque sin omitir otros niveles educativos- obliga a los docentes a emplear las técnicas clásicas: repasar las normas, exámenes, resúmenes, dictados y listas de palabras; sin embargo, las prácticas de antaño no parecen haber logrado los resultados esperados (de otra forma no se estaría hablando hoy de esta problemática). Además, aunque abunden manuales de redacción y ortografía para profesores, la realidad educativa nos dice que las propuestas difícilmente pueden llevarse a cabo porque no se dispone de los elementos necesarios, sobre este punto expresan la mayoría de profesores: "estamos muy cansados de hermosas teorías que son inaplicables debido a que exigen unas condiciones que en el aula no podemos ni soñar" (Gabarró y Puigarnau, 1996), dadas las precarias condiciones que prevalecen en las instituciones educativas: humanas, materiales y pedagógicas, entre otras.

Por otro lado, resultaría iluso y serviría de poco invitar a los jóvenes - como intentan muchos profesores- a dejar de practicar los recursos de la tecnoescritura en los espacios virtuales, porque, como lo 
muestra la realidad actual, en muchas experiencias académicas, esta forma de codificar es útil y valiosa en aquellos sitios, además, como igualmente se ha intentado exponer, es una posesión simbólica de pertenencia. Debe entenderse: las codificaciones alternativas seguirán evolucionando, compensando limitaciones propias del canal por el cual transitan, y, por ende, continuarán empleándose; hay que encontrar medios para auxiliar, no para coartar.

Es importante resaltar que la enseñanza de este conocimiento cuenta con una vastedad de recursos para su adquisición, recuperación y reforzamiento, el presente artículo-capítulo podría limitarse a concretar una secuencia didáctica (de las tantas que hay) que proporcione una aparente solución al escenario descrito, no obstante, sería ingenua una resolución así, ejercicios y estrategias existen, pero muestran ser insuficientes o irrealizables como lo mencionan Gabarró y Puigarnau, ya sea por falta de un proyecto educativo claro, por una inadecuada ejecución, falta de planeación o la escases de tiempo, este último aspecto es el más significativo en las aulas, pues la mayoría de estos recursos exigen demasiado tiempo a los docentes, el cual, se sabe, es escaso y se prefiere destinar a cumplir los objetivos del programa.

Anteriormente se mencionó, cómo la enseñanza dirigida es considerada por diversos autores como una buena opción para formar en el arte de escribir con pulcritud, pero ésta escasamente puede aplicarse ya que demanda demasiada dedicación al tema y, se debe recalcar, que en nuestro modelo educativo lo que menos se tiene en las escuelas es tiempo para ello.
Con lo enunciado hasta este punto tampoco se debería concluir la inexistencia de opciones efectivas en la práctica, ejemplo de una alternativa viable es el método didáctico para alumnos de secundaria propuesto por María Teresa Pérez Tapia (2008) el cual consiste en la reescritura manuscrita - planificada y sistematizada- de textos breves o muy breves de autores literarios de prestigio. Este método, que la autora puso a prueba, arrojando resultados positivos, según refiere, consiste en desarrollar las destrezas ortográficas, la competencia y el gusto por la lectura, la conciencia lingüística, el agrado por la corrección en los escritos y, en general, simpatía por la escritura.

Tomando como inspiración el mencionado aporte de Pérez Tapia, la experiencia vivida en el curso para profesores Aplicación de estrategias de lectura y escritura para potenciar los aprendizajes impartido en la Dirección General de Orientación y Servicios Educativos de la UNAM y diversos planteamientos de un sinnúmero de especialistas, la alternativa que se pretende desarrollar no intenta ser un recetario de actividades para acuñar y recuperar solo la destreza ortográfica, más bien aspira a edificarse como una reflexión crítica que incite a repensar ciertas prácticas escolares relacionadas con la lectura y escritura, y considerar éstas como posibles vías de atención a este apremiante problema.

Podría considerarse demasiado simple o vago proponer repensar la lectura y la escritura para tratar una problemática compleja con muchos ángulos desde los cuales puede analizarse, pero todo cuaderno para aprender y enseñar ortografía (sea para profesores o de autoaprendizaje) plantea 
que los principales medios para acuñar esta destreza se encuentran en leer y escribir constantemente.

Hay que recordar algo que se ha mencionado ya en repetidas ocasiones, la lectura provee estímulos visuales, es decir, proporciona modelos literarios de ortografía y gramática, incorpora vocabulario nuevo y refuerza el que ya se tiene, además, representa una fuente valiosa de conocimiento; el acto de escribir, por otro lado, sirve para llegar gradualmente a un dominio del léxico básico y habitual, es altamente motivador para quien lo realiza (si cumple con ciertas condiciones didácticas), afina las habilidades del pensamiento para estructurar información y simboliza la ejercitación de la memoria muscular (elemento esencial en la adquisición del hábito ortográfico), la cual no solo se limita a los movimientos de la mano en textos manuscritos, también abarca la escritura "tecleada" o digitada, pues las manos y los dedos recuerdan la posición de las teclas y el recorrido que hacen para llegar a ellas.

Aunque algunos métodos punitivos (como escribir cien veces correctamente una palabra en la que se falla continuamente) muestran resultados deseados (no volver a incurrir en el error), su práctica provoca que la ortografía deje de ser un medio para convertirse en un fin, y no solo ello, también incita el desdén a quienes la estudian. Además, en vista de la dificultad para poner en marcha estrategias que requieran un tiempo considerable de aplicación, y a esto se suma el desinterés expreso de muchos profesores en dedicar espacio para su ejercicio, se hace necesario regresar a lo elemental, voltear la mirada hacia el acto de leer y escribir, y encaminar la reflexión en analizar el por qué su ejercicio (praxis) falla en las escuelas.

\section{Aprender a leer y escribir en la escuela: papel decisivo de la didáctica, en tanto teoría y práctica de la enseñanza}

Muchos de los beneficios que brindan leer y escribir constantemente son conocidos por los expertos y las autoridades escolares (amplía el vocabulario, ejercita la imaginación, entrena la capacidad para estructurar información, aumenta el bagaje cultural, proporciona modelos de ortografía y sintaxis, entre otros) de tal forma que constituyen el pilar fundamental en todos los niveles educativos y se procura - al menos en el imaginario- promover la práctica constante. El objetivo primordial de la escuela primaria siempre ha consistido en enseñar a usar el código de la lengua escrita y la aplicación de las cuatro operaciones aritméticas básicas, se puede afirmar que la alfabetización en estos primeros años de enseñanza básica se realiza de forma "exitosa" pues los alumnos son capaces de leer en voz alta y en silencio, toman dictado, redactan y transcriben textos básicos, tales como cartas, poemas, resúmenes, recados, etc.

En educación secundaria se pretende el perfeccionamiento de dichas habilidades a través de promover el gusto por la lectura, formando para la compresión lectora, afinando las destrezas técnicas en la expresión escrita y estimulando la inventiva creativa con la elaboración de diferentes géneros discursivos, no obstante, es un hecho, no sucede así. Diversos autores (Jimé- 
nez y Coria, Monje Margeli, Carlos Dido, Pérez Tapia, Gabarró y Puigarnau, Ferreiro y Gómez Palacio) mencionan que en la enseñanza secundaria, independiente al campo de conocimiento estudiado, la mayor parte de las actividades de aprendizaje están relacionadas con leer y escribir: estudiar los textos, tomar apuntes manuscritos, elaborar resúmenes, informes de prácticas, dictados, exposiciones, etc.; sin embargo, a pesar de la variedad de situaciones de aprendizaje efectuadas con base a las habilidades mencionadas, éstas no terminan siendo provechosas ya que tienden a desarrollarse como actividades cuasi mecánicas; en otras palabras, la lectura es un acto automatizado, un ejercicio de dicción a lo sumo, y la escritura se emplea como una traslación del lenguaje oral. Monje Margeli (1993) expone sustantivamente este panorama y enuncia:

[...] en nuestras escuelas se ha aprendido a leer y a escribir, pero de todo el proceso de aprendizaje de la lectura y de la escritura, con frecuencia el niño -que luego se ha convertido en adulto- se ha quedado anclado en una primera fase [...] la escuela en general apenas si sólo se ha preocupado de enseñar la mecánica, es decir, ha centrado todo su interés en enseñar a codificar y a decodificar, objetivo que se consigue con una relativa rapidez, mientras ha olvidado otros aspectos fundamentales, pero de objetivos menos controlables, o continuamente prorrogables a nuevas metas, dado que a leer y escribir se empieza a aprender, pero no se acaba nunca. Así, la motivación, la expresión, la comprensión, muchas veces han sido consideradas sólo superficialmente, o simplemente ignoradas.
En efecto, actividades realizadas excesivamente como la lectura en voz alta y el dictado, hacen creer a los estudiantes que leer y escribir consiste únicamente en una prueba de dicción y en la transcripción de la oralidad, desde luego estas técnicas son auxiliares en la enseñanza, además sirven como medios específicos para examinar la presencia de errores de pronunciación que podrían repercutir en la ortografía a través de la lectura y la escritura y para afinar las habilidades motoras manuscritas, sin embargo, nunca se hace explícito a los alumnos los fines de las actividades de aprendizaje, peor aún, los mismos profesores a veces no conciben que éstas pueden "automatizar" dichas habilidades, despojándolas de todas las bondades que podrían aportar al estudiante. Partiendo de esta premisa, es que la Escuela Nueva tendió a considerar toda transmisión de contenido como mecánico y todo mecanicismo como anticreativo, así como todo automatismo como negación de la libertad.

Sin embargo, es necesario establecer que el automatismo es condición de libertad y que no es posible ser creativo sin dominar determinados mecanismos o mecanicismos. Esto ocurre con lo aprendido en los demás niveles educativos; así, por ejemplo, para aprender a manejar un automóvil es necesario repetir constantemente las mismas acciones o actos hasta familiarizase con ellos, después ya no será necesaria la repetición. De cuando en cuando se practican con desenvoltura y facilidad. En el proceso de aprendizaje esas acciones, aparentemente simples, exigirán razonable concentración y esfuerzo hasta ser fijadas y pasen a ser ejercidas, por así decirlo, automáticamente. 
La libertad, entonces, solo se logrará cuando las acciones sean dominadas. Y esto ocurre en el momento en que los mecanismos son fijados. Por tanto, por paradójico que parezca, es exactamente cuándo se logra el nivel en que las acciones son desarrolladas automáticamente, que se está en condición de ejercer, con libertad, el proceso que comprende las referidas acciones. Entonces la atención se libera, no siendo ya necesario ejecutar cada acción; en ese momento es posible no nada más solo manejar el automóvil libremente, sino también ser creativo en el ejercicio de esa actividad. Y solo se llega a ese punto cuando el proceso de aprendizaje, como tal, se completó; por ello, es posible afirmar que el aprendiz, en el ejercicio de aquella actividad que es objeto de aprendizaje, nunca es libre. Cuando sea capaz de ejercerla libremente, en ese momento dejó ser aprendiz (Saviani,1994).

Aunado a estas circunstancias, la estrategia didáctica es un elemento importante a tomar en cuenta, puesto que la posición de los profesores frente a ciertos conceptos clave, determinan la forma en que se desarrolla y enseña cualquier conocimiento y habilidad - lo cual engloba la enseñanza de la lectura y escritura-; según diversos autores, pueden distinguirse por lo menos, tres corrientes didácticas, cada una con sus propias concepciones y características particulares; para efectos de este artículo, aquí las llamaremos convencionalmente: didáctica tradicional, tecnología educativa y didáctica crítica y/o alternativa (Morán, 2005).

En la didáctica o educación tradicional el profesor se apega fielmente al programa de estudio que las autoridades escolares dictaminan (sea expreso o incluido en el libro de texto), el aprendizaje es considerado una reproducción de la realidad, por lo cual se ejercitan las capacidades para retener y repetir información. Un signo característico de este enfoque de la didáctica es el enciclopedismo, representado por el gran cúmulo de conocimientos que el alumno tiene que aprender; por otro lado, los contenidos se consideran como algo estático, acabado y legitimado, con pocas posibilidades de análisis y discusión, o de objeción. En esta educación tradicional, dice Paulo Freire (1976):

[...] el educador aparece como agente indiscutible cuya indeclinable tarea es "llenar" a los educandos con contenidos de su narración [...] Tal es la concepción "bancaria" de la educación, en que el único margen de acción que se ofrece a los educandos es el de recibir los depósitos, guardarlos y archivarlos.

De esta forma, explica el mismo Freire, el educador es quien educa, sabe, piensa, habla, disciplina, prescribe y actúa, es, en resumen, el sujeto del proceso de enseñanza y aprendizaje; el educando, por su parte, es quien no sabe, quien escucha dócilmente, el que debe ser disciplinado, quien sigue la prescripción, quien tiene la ilusión de que actúa, quien se acomoda al contenido establecido, quien debe adaptarse a las determinaciones del educador, es, en resumen, un mero objeto no un sujeto de aprendizaje. Así, según esta perspectiva de la didáctica:

El alumno ideal es el alumno angelical, sin cuerpo, sin movimiento. El maestro se dedicará a defender y pro- 
mover las actividades intelectuales, poniendo al estudiante en contacto con el saber ya poseído proporcionándole, le guste o no, las disciplinas que se considera formadoras para el buen uso de la razón (Blanco, 1982).

Las actividades de enseñanza se limitan a la exposición oral y la transcripción de la misma a la hoja en blanco, y los recursos empleados para estas actividades generalmente abarcan: libro de texto, pizarrón, láminas y carteles. Con esta concepción de enseñanza, de aprendizaje $y$, consecuentemente de educación; la evaluación se reduce a comprobar los conocimientos vertidos al alumno mediante la aplicación de exámenes de diferentes características y denominaciones, aunque sigue prevaleciendo lo que genéricamente se llama prueba objetiva: respuesta breve, complementación, correlación, opción múltiple, falso/verdadero, entre otros.

La tecnología educativa, como corriente didáctica cuyo andamiaje teórico-metodológico se expresa en la sistematización de la enseñanza, surge en los sesenta, pero se consolida en América Latina en los setenta, se apoya básicamente en los supuestos de la psicología conductista, y entiende al aprendizaje: como un conjunto de cambios y/o modificaciones en las conductas más o menos duraderas que se operan en el sujeto como resultado de acciones y experiencias determinadas $y$, a la enseñanza, como el control de la situación en la que ocurre el aprendizaje. Aunque en esta perspectiva el docente sigue teniendo el control de la situación educativa, aunque su autoridad ya no resida tanto en el dominio de los contenidos [...] sino en el manejo diestro de las técnicas, por eso suele denominársele en esta visión tecnicista, como un ingeniero conductual (Morán, 2005).

Bajo esta tendencia didáctica, el docente se apoya, como decíamos, en la sistematización de la enseñanza al especificar minuciosamente en su programa objetivos de aprendizaje conductuales, técnicamente formulados, en los cuales se describen aquellas conductas unívocas, medibles y verificables que el alumno logrará después de cierto periodo de enseñanza. En cuanto a los contenidos, pasan a segundo plano, se entienden como algo ya dado y validado por la institución educativa y sus grupos de expertos en planeación [...] lo importante, en esta tendencia, no son los contenidos, sino las conductas a lograr.

Una de las características esenciales de esta corriente didáctica se distingue por el rechazo a la improvisación en las actividades de enseñanza, todo procedimiento, técnica o recurso han sido seleccionados y organizados con anticipación, privilegiando así la estructuración de los momentos de aprendizaje, planeación concretada en cartas descriptivas (elementos que organizan y describen temas, objetivos, recursos, técnicas, tiempos, resultados). El papel del alumno, en este escenario, no difiere mucho del modelo didáctico precedente, es básicamente un objeto a manejar que debe ser entrenado para la eficiencia y la eficacia compitiendo con otros y contra él mismo.

La evaluación, en concordancia acorde a esta línea de análisis, se entiende como elemento primordial de todo proceso de enseñanza, "se ocupa de la verificación y la comprobación de los aprendizajes plan- 
teados en los objetivos, busca evidencias exactas y directamente relacionadas con las conductas formuladas en dichos objetivos" (Morán, 2005), para tal fin, el predominante uso de pruebas objetivas, que buscan los principios técnicos de objetividad, confiabilidad y validez, son un distintivo más de esta tendencia didáctica.

En oposición a las posturas anteriores, los postulados de la didáctica crítica o alternativa rechazan las homogéneas prácticas para enseñar a masas y la uniformidad de los grupos, reconociendo así la heterogeneidad de los elementos que participan dentro del proceso de enseñanza-aprendizaje. Esta corriente, por el contrario, busca renovar los supuestos teóricos y las perspectivas de la educación, cuestionando severamente el autoritarismo de las instituciones educativas y le asigna el poder a los agentes involucrados: profesores y alumnos; más allá de proponer técnicas, su propuesta se concentra en analizar y reflexionar sobre la praxis docente particular, desechando las rígidas e instrumentalistas concepciones educativas tradicionales, centrando, para ello el interés no en relevar el producto sino también y, de manera privilegiada, el proceso, es decir, destacando la importancia de la enseñanza y el aprendizaje como binomio inseparable. Enfatizando que en una docencia renovada, derivada de esta corriente, importa mucho el qué se aprende, el cómo se aprende y, sobre todo, el para qué se aprende. Cabe señalar, que estos planteamientos son válidos no solo para la enseñanza de la lectura y la escritura sino para cualquier otro objeto de estudio.

Este nuevo posicionamiento considera a la enseñanza y al aprendizaje como proce- sos dialécticos, "se apoya en que el movimiento que recorre un sujeto al aprender, no es lineal, sino que implica crisis, paralizaciones, retrocesos, resistencias al cambio, etc." (Rodríguez, 1976).

En esta concepción de enseñanza y aprendizaje es necesario seleccionar experiencias idóneas para que el alumno realmente opere sobre el conocimiento $y$, en consecuencia, el profesor deje de ser el mediador entre el conocimiento y el grupo, para convertirse en un promotor de aprendizaje a través de una relación cooperativa.

Bajo estas premisas, todos aprenden de todos, los alumnos aprenden a aprender y el docente aprende a enseñar, de esta manera los estudiantes ya no son meros objetos abstractos, "sino un ser humano en el que todo lo vivido, su presente, su pasado y su futuro, aun para ser negado, está en juego en la situación" (Santoyo, 1981).

Los contenidos de un programa en esta perspectiva no son algo acabado y cerrado, están sujetos a cambios y al enriquecimiento constante; así mismo, éstos deben ser lo menos fragmentados posible. A su vez, las actividades de aprendizaje deben pensarse como situaciones o experiencias que promuevan la participación de los estudiantes y desarrollen las habilidades superiores del pensamiento, como el análisis, la crítica, la reflexión, la interpretación y la creatividad.

Dado que la didáctica crítica o alternativa reconoce constantes momentos de ruptura y reconstrucción, los momentos de aprendizaje plantean una dimensión distinta a los modelos antecesores, en este sentido Azucena Rodríguez (1976) propone tres momentos metódicos en que las situa- 
ciones de aprendizaje pueden organizarse:

a) Apertura, es una primera aproximación al objeto de conocimiento; b) Desarrollo, es un análisis del objeto para identificar sus elementos, pautas, interrelaciones, y c) Cierre, es un tercer momento de reconstrucción del objeto de conocimiento, producto del proceso seguido, correspondiendo a estas distintas fases del conocimiento diferentes procedimientos de investigación y de operaciones mentales: observación, descripción, experimentación, comparación, inducción, deducción, análisis, síntesis y generalización.

b) En cuanto a la evaluación, esta corriente didáctica expresa la necesidad de replantearla tanto en su concepción como en su práctica, para no reducirla a un simple auxiliar administrativo, abocado a asignar calificaciones (noción tradicional de medición) o cayendo en propuestas meramente instrumentales; más bien se propone redefinir la evaluación para que ayude sustantivamente al proceso de enseñar y aprender, analizando las condiciones internas y externas que lo determinan, o bien, aquellas que lo entorpecen y/o distorsionan, brindando información oportuna y valiosa para el docente, los alumnos, los padres de familia y las propias autoridades.

Definitivamente en la actualidad, a pesar de los cambios y reformas promovidas e implantadas por el gobierno federal en los niveles de educación básica y media supe- rior su puesta en marcha ha carecido de las condiciones indispensables para hacerlas una realidad. Sobre todo porque no ha tomado en cuenta la participación real de los profesores, que son los agentes fundamentales porque son los que concretan dichos proyectos educativos en la cotidianidad del trabajo pedagógico. Esta situación ha llevado a que las escuelas, con todo el aparato académico-administrativo se preocupan por enseñar a leer y escribir como medio para acumular conocimientos, ignorando con ello las condiciones de aprendizaje, la heterogeneidad de los alumnos y los momentos de ruptura y reconstrucción que demanda toda reforma educativa.

La falta de formación pedagógico-didáctica de los profesores en los niveles aludidos, reducen la lectura y la escritura a un acto mecánico, es decir, dominar el código escrito sigue siendo un fin en sí mismo, en lugar de concebirse como una herramienta universal en la adquisición y transformación del conocimiento; se ha olvidado que existe un mundo entre "aprender a leer" y "leer para aprender", citando nuevamente a Monje Margeli, apuntamos: "con frecuencia la escuela ha enseñado a leer y a escribir, pero no ha creado lectores ni escritores, porque para ello hace falta algo más que dominar el código de la lengua escrita".

Las palabras de Monje Margeli (1993) evidencian una verdad incómoda: la práctica docente de la educación básica (y en los otros niveles también la escuela secundaria) está repleta de experiencias que demandan leer y escribir, desafortunadamente éstas no exigen una compleja acción cognitiva que requiera conciencia, control 
y atención para realizarlas, de tal manera que los docentes dan por acabado el aprendizaje de la lectura y escritura cuando los aprendices dominan el código de la lengua escrita. Por ello, no se forman lectores ni escritores, porque son habilidades más complejas que el simple acto de recorrer las líneas de un texto con los ojos o copiar las mismas en una hoja en blanco, y es por esto, que también tenemos alumnos con faltas de ortografía increíbles, porque ésta se aprecia solamente cuando se sabe para qué sirve, es decir, cuando el lector o escritor es capaz de establecer un vínculo con el texto fuera del acto mecánico.

G. Wells (citado por Monje Margeli) propone cuatro niveles en la adquisición y el dominio de la lengua escrita: el primero, el ejecutivo, se entiende como la traslación del mensaje del código oral al código escrito y viceversa; el segundo nivel, el funcional, se refiere a la lengua escrita como un hecho de comunicación interpersonal, que consiste en poder afrontar necesidades cotidianas de la sociedad, tales como leer instrucciones, revistas, el periódico, etc.; en el tercer escalón, el instrumental, el estudiante es capaz de interpretar el enunciado de un problema de matemáticas, o estudiar un tema de historia, porque puede servirse instrumentalmente de los textos; y el último nivel, el epistémico, se refiere al control del escrito como una manera de pensar y de utilizar el lenguaje de una forma creativa y crítica, es decir, la estructuración del lenguaje y la ordenación del pensamiento están al servicio el uno del otro.

De acuerdo con esta nomenclatura, se puede aseverar que en las aulas de la edu- cación básica y, las más de las veces, hasta el bachillerato, solo se "instruye" hasta el nivel funcional, se asume que tenemos alumnos capacitados para leer textos extensos y elaborar escritos sencillos, pero no significa que sean buenos lectores o escritores.

Ciertamente en nuestras escuelas no existe una verdadera formación en lectoescritura, únicamente hay alfabetización, pero ¿por qué sucede esto? Además de la metodología tradicional imperante en las escuelas, especialistas atribuyen esta situación al hecho de que los estudiantes no entablan una correspondencia real con los textos, dado que la lectura y escritura no se conciben como elementos cotidianos con un valor real fuera del ámbito escolar, y esta escisión con el mundo de las letras es causada a su vez por una falta de interés hacia dichas actividades. Monje Margeli (1993) manifiesta al respecto: "Se produce una pérdida de relación con la realidad, cuando lengua, lectura y escritura deberían seguir desarrollándose ligadas a la realidad de los alumnos, a sus intereses, y a las funciones específicas de los propios actos de lectura y escritura".

En otras palabras, recordando lo expresado por Jiménez y Coria:

[...] es bien sabido que todo conocimiento que no encaje dentro de los intereses, experiencias, necesidades, posibilidades, etc., de los niños, carece de valor educativo, eso es de lo que adolece la enseñanza de la lectura y escritura, pues es una realidad: los colegios no toma en cuenta el interés ni la motivación de los estudiantes.

Mencionan Chartier y Hébrard (2000) que la escuela hace elecciones de lecturas 
para las nuevas generaciones y selecciona de entre el corpus de todo lo legible aquellos textos que estima convenientes para constituir una cultura común, por supuesto el estudiante es ajeno a estas decisiones, de tal forma que, hay que aceptarlo, en su mayoría éste no siente agrado o interés por las mismas, no se identifica con ellas y, por ende, no las disfruta ni se acerca por voluntad genuina; incluso los buenos alumnos, sugieren los mismos autores, "no leen por placer personal, sólo lo hacen por requerimientos-necesidades escolares. Al respecto, Lasso Tiscareno (2004) comparte una reflexión similar:

[...] profesores y estudiantes -en el mejor de los casos- se limitan a consultar sus libros de texto, leen por obligación, o sea que leen mal, sin comprender cabalmente y no obstante su alta escolaridad, no han adquirido el hábito y descubierto el placer de la lectura [...] No basta leer muchos libros de texto, ni pasar muchos años en la escuela para convertirse en auténticos lectores. Usualmente, desde que se culmina la primaria, la mayoría de los niños no tienen libros ni revistas en su casa. Ni existen condiciones de acceso a bibliotecas donde consultarlos. La mayoría de los mexicanos no están acostumbrados a ver leer a sus padres $y$, a menudo, en muchos de los hogares, en el mejor de casos, ocasionalmente solo se lee el periódico.

Esta ruptura con la cultura escrita de la que hablan Chartier-Hébrard y Lasso Tiscareno se refleja en las estadísticas, la Encuesta Nacional de Lectura 2012 arrojó datos preocupantes: el estudio registró que sólo el $46.2 \%$ de los encuestados aseguraron leer libros, es decir, aproximadamente
4 de cada 10 personas, mientras que el promedio anual de libros que leemos los mexicanos es de 2.94; esta misma investigación indicó además, "se observa una caída en la frecuencia de lectura a partir de los 18 años, edad a la que la mayoría de los jóvenes terminan sus estudios y es cuando leen menos, incrementándose la disminución de lectura notablemente con el aumento de la edad" (Encuesta Nacional sobre Lectura, 2012).

Entre otras cosas, el documento destacó que las principales razones expresadas por los mexicanos para no leer, o por las cuales no leerían, se encuentran: por falta de tiempo, por dedicarse a otras actividades recreativas o porque no les gusta leer. Naturalmente este rechazo a la lectura está ligada con la escritura, "[...] con frecuencia, nos encontramos a personas que no saben escribir porque no saben leer, o con más propiedad: personas que no saben escribir porque nunca leen" (Lasso Tiscareno, 2004).

Con lo formulado hasta este punto no se puede ocultar algo tan evidente: somos una sociedad ágrafa y huérfana de la lectura, tenemos una generación que muestra apatía hacia los libros y la cultura escrita en general; $y$ sin embargo, atestiguamos un fenómeno interesante: por un lado, México es parte de los países con menor índice de lectura en el mundo, pero también pertenecemos a los países con más presencia en redes sociales, además del notable aumento que año con año se muestra tanto en los usuarios de Internet como en el tiempo dedicado a éste; es decir, tenemos un sociedad que no está habituada a leer, y a su 
vez somos una potencia en usuarios de plataformas sociales virtuales, sitios donde el lenguaje escrito figura como el medio predominante para la comunicación. No obstante, esta situación es engañosa, la participación en los espacios virtuales demanda saber emplear el lenguaje escrito, pero los intercambios ahí suscitados no son en su mayoría actividades que requieran algo más que estar capacitado para codificar y decodificar mensajes, es tal como lo plantean López y Ciuffoli, (2012) refiriéndose a la escritura en redes sociales:

Más que una práctica letrada, se trata de una conversación oral y corporal distribuida que se establece a través de los 27 caracteres del teclado pero principalmente utilizando el mouse. Se trata de una comunicación que conserva los tiempos y códigos del habla en la mayor parte de las acciones.

Entonces, recapitulando: la enseñanza/ recuperación de la ortografía, separada del objeto al cual sirve (escritura), carga en demasía su estudio, el ideal - de acuerdo a diversos autores - es que la ortografía (ésta) se aprehenda tácitamente a través de la lectura y escritura, la primera ofrece modelos ortográficos (estímulos visuales), la segunda representa la ejercitación del léxico (desarrollo de la memoria muscular); sin embargo, enseñanza básica (la escuela secundaria) se muestra ineficiente en el perfeccionamiento de las habilidades mentales relacionadas con dichas actividades, pues sólo alfabetiza, capacita a los estudiantes para usar el lenguaje escrito a niveles ejecutivo y funcional, pero no forma lectores ni escritores porque no propicia ni desarrolla una sensibilidad hacia cultura escrita, ni promueve al hábito de leer por placer, y ello sea posiblemente uno de los tantos factores con más peso en el momento de acuñar el ciberdialecto de forma no intencionada, ya que si los alumnos no leen ni escriben por gozo, cuando se adentran a espacios virtuales donde tienen que redactar para comunicarse, la escritura se vuelve significativa para ellos, las redes sociales se convierten así en lugares donde ésta tiene un sitio y un fin, desafortunadamente, como mencionan López y Ciuffoli, no es una práctica letrada. Tal vez este fenómeno sea una prueba que demuestra cómo leer y escribir por iniciativa personal permite apropiar y ampliar el lenguaje, aunque bueno, en esta situación no se apropian palabras convencionales de nuestro vasto idioma, sino que se adquieren las ya mencionadas neografías.

\section{Esbozo de una estrategia pedagógica para la lectura y la escritura}

Ante el panorama planteado, uno de los caminos posibles para favorecer la formación de lectores y escritores apunta a dotar la lectoescritura, en espacios escolares, con significación, meta que -entre otras cosas- podría conseguirse si se trabaja la motivación. No sería acertado dejar pasar desapercibido el fenómeno de escritura en las redes sociales, pues si bien no es una práctica académica, es un hecho que en esos espacios los jóvenes leen, indagan, escriben, opinan, participan activamente, sacian su curiosidad cuando un tema interesante se presenta... todas estas actividades las realizan voluntariamente; quizá para un adolescente la literatura clásica no sea tan atrayente y menos aún los ejercicios 
de escritura encontrados en los libros de texto, pero éstos pueden devorar artículos completos que analizan si el videojuego del verano será o no un éxito, leen con minuciosidad las 101 dietas de personajes famosos o devoran en pocos días el Best Seller de moda, escriben su opinión sobre el último éxito de un determinado cantante, defienden u objetan con extensas líneas si un video viral es real o falso o manipulado.

Las redes sociales se alzan así como diarios virtuales públicos donde la retroalimentación a base de la escritura es constante. Sin duda, resultaría cuestionable si la información consumida y compartida es relevante, pero es una realidad que el Internet le está ganando la batalla a las instituciones educativas en motivar e incentivar la lectura y escritura entre los jóvenes, pues en dichas plataformas leer y escribir son herramientas apreciadas y significativas, se está participando en una comunicación constante donde la palabra escrita muestra su verdadero alcance. Es necesario aprovechar esta situación, el Internet nos está dando una lección de cómo fomentar la cultura escrita en la juventud, y la escuela podría asimilar pequeñas pautas inspiradas directamente del mundo virtual.

Este posible vínculo entre la lectoescritura, el ciberespacio y la formación de lectores y escritores es un tema relativamente reciente, por lo que se halla muy poco material al respecto. Daniel Cassany y Denise Hernández, por ejemplo, en su artículo “iInternet: 1; Escuela: 0?” exponen esta idea al reseñar el caso de Mei, una estudiante de 19 años de Barcelona que no puede aprobar el Bachillerato de Letras a pesar de llevar una actividad diaria y variada en la Red, lugar donde publica para sus amigos una novela de su autoría y gestiona foros de literatura.

Durante el desarrollo del texto, Cassany y Hernández (2012) insinúan lo que se ha esbozado en líneas anteriores: las prácticas de lectura y escritura en Internet cuentan con ciertos elementos que no están presentes en la enseñanza formal, y esta carencia puede ser una de las causas de que algunos estudiantes no encuentren motivación ni significado en las actividades escolares. Concretamente, expresan dichos autores, Internet despierta el interés de los jóvenes porque ahí:

- leen y escriben voluntariamente géneros discursivos propios (ficciones, historias fantásticas o realistas) con procedimientos particulares (comentario, mezcla de varios idiomas y registros, uso de recursos literarios variados) y con el capital lingüístico que ya dominan y que eligen;

- lo hacen al interior de grupos o pandillas informales de amigos que actúan como "comunidades de práctica", en donde unos enseñan a otros cooperativamente y comparten en línea y fuera de línea los recursos lingüísticos de cada cual;

- tienen audiencias auténticas, que crean situaciones reales de comunicación, en donde la lectura y la escritura son comunicativas y buscan significados;

- la interacción con estas audiencias tiene componentes personales y emo- 
tivos, de tal forma que leer y escribir se relacionan con la construcción de la identidad social y acaban siendo una herramienta para establecer vínculos emocionales más fuertes (leer y escribir no son ni una finalidad en sí ni una habilidad académica autóno$\mathrm{ma})$.

Estos autores concluyen su apartado enunciando: "En definitiva, si las asignaturas que ha suspendido Mei cumplieran alguno de estos puntos quizás ella las sentiría más cercanas y tendría más posibilidades de aprender y de aprobarlas”.

Lo que se está gestando en espacios virtuales es claramente novedoso y dinámico, y no sería inteligente desacreditarlo o ignorarlo solo porque los productos ahí realizados son incompletos o carecen de toda formalidad académica; según el texto de Cassany y Hernández, las diferencias entre las actividades de lectura y escritura en la red y la escuela se resumen en que las primeras se desarrollan en contextos sociales auténticos, mientras que las tareas propuestas en las aulas carecen de relevancia para los jóvenes.

La siguiente tabla -recuperada del documento original- contrasta las características de un contexto social auténtico -tareas en la vida- y un contexto escolar -tareas en la escuela:

\begin{tabular}{|l|l|}
\hline TAREAS EN LA VIDA & $\begin{array}{l}\text { TAREAS EN LA } \\
\text { ESCUELA }\end{array}$ \\
\hline $\begin{array}{l}\text {-Vinculadas con } \\
\text { prácticas sociales } \\
\text { significativas para el } \\
\text { estudiante. }\end{array}$ & $\begin{array}{l}\text {-Desvinculadas de } \\
\text { las prácticas sociales } \\
\text { del estudiante. Sin } \\
\text { significación. }\end{array}$ \\
\hline $\begin{array}{l}\text { La lectura y la escritura } \\
\text { se vinculan con la } \\
\text { identidad global del } \\
\text { sujeto y del entorno. }\end{array}$ & $\begin{array}{l}\text { Vinculadas a una } \\
\text { "realidad letrada } \\
\text { escolar", que el sujeto } \\
\text { no valora o que no } \\
\text { conecta con el resto de } \\
\text { su persona. }\end{array}$ \\
\hline $\begin{array}{l}\text { Hay interacción } \\
\text { auténtica. }\end{array}$ & $\begin{array}{l}\text { Tarea escrita } \\
\text { individual, callada. }\end{array}$ \\
\hline $\begin{array}{l}\text { Se generan estrategias } \\
\text { personales y diversas } \\
\text { de resolución. }\end{array}$ & $\begin{array}{l}\text { Hay que usar } \\
\text { procedimientos } \\
\text { estándar } \\
\text { preestablecidos } \\
\text { (algoritmos, normas). }\end{array}$ \\
\hline $\begin{array}{l}\text { Búsqueda de } \\
\text { significado. }\end{array}$ & $\begin{array}{l}\text { Aplicación mecánica y } \\
\text { sin sentido. }\end{array}$ \\
\hline $\begin{array}{l}\text { Es un saber práctico } \\
\text { cotidiano. }\end{array}$ & $\begin{array}{l}\text { Es un saber teórico } \\
\text { académico. }\end{array}$ \\
\hline
\end{tabular}

Concretando algunas estrategias didácticas y/o pedagógicas expuestas en apartados anteriores de este mismo escrito, y atendiendo lo ofrecido en este inciso, esbozamos una propuesta para abordar el serio y vital problema de la lectura y escritura.

Por consiguiente, lo indicado es propiciar la generación de estos contextos sociales auténticos en la escuela; no obstante, aventurarse a idear grandes cambios a los sistemas de enseñanza es irrealizable, pero quizá resultaría factible proponer la apertura de pequeños momentos significativos de lectura y escritura, quizá tareas para realizar en casa, complementarios a la planeación ya establecida formalmente, donde se expresen situaciones de aprendizaje que replanteen ciertas concepciones pedagógicas 
y/o didácticas, considerando las siguientes consignas:

Primera consigna. Tomar en cuenta los intereses de los alumnos. Es un hecho que la escuela - como institución social- necesita difundir una cultura común con base en lecturas específicas, pero se sabe que éstas por lo general no motivan a los estudiantes, pues son ajenas a ellos, al contexto y las aficiones particulares, cabe plantearse ¿por qué las plataformas virtuales funcionan tanto? En el apartado dedicado al tema se expusieron diversos motivos de su aceptación entre el público juvenil, pero gran parte de su éxito se debe a que no están temáticamente preestablecidas, de tal forma que en ellas caben todos los contenidos, otorgando a sus usuarios la libertad de moverse sobre la información y los intereses individuales.

Sería absurdo pensar en replantear el corpus de textos que las autoridades educativas han seleccionado para constituir dicha cultura, pero pueden retomarse los materiales escritos que los adolescentes ya conocen y a los cuales se han acercado fortuitamente, así como incentivarlos a explotar esos intereses; por ejemplo, si un pequeño grupo ha leído la novela romántica de moda, proponer indagar otras obras del mismo autor, o si se espera con ansia la salida del videojuego del que toda la comunidad gamer está hablando, plantear leer los pre-análisis de las revistas especializadas, o si alguien es amante de los gatos, sugerir exploren en webs, revistas y wikis los alimentos que pueden enfermarlos... los intereses inmediatos siempre estarán ahí y continuamente habrá un tema del que los jóvenes podrán hablar como "expertos" porque algo han leído al respecto, hay que aprovechar eso, así se estaría fomentando no solo la lectura, sino también la investigación.

Para Lasso Tiscareno la lectura es: "una afición, difícilmente se enseña, más bien se contagia, ese es el objetivo de este primer punto: contagiar el gozo por las letras". Para este fin es necesario erradicar la clásica concepción del estudiante visto como una tabula rasa; ya decía Luis Porter (1996) que:

Los aprendices llegan a la escuela con un repertorio cultural personal compuesto por imágenes y vivencias propias de su crecimiento, mas [...] lo irónico, lo trágico, es que el profesor tiende a menospreciar esa riqueza interna que el estudiante ya posee, $y$ no la utiliza como fuente de inspiración y de recursos, por el contrario, intenta sustituirla con sus prejuicios, su bibliografía, su personal nicho constreñido y por su particular currículum.

Bien podría argumentarse -muchos profesores lo hacemos- que los jóvenes sólo leen basura o están interesados en temáticas frívolas, por lo que tomar en cuenta sus aficiones no sería acertado para la formación de lectores; sin embargo, con esta acción no se pretende avivar el tema que a ellos interesa, sino mostrar la lectura como una ventana que amplía el horizonte, es decir, se trata de enlazar los aprendizajes con la realidad inmediata de los individuos, tal como menciona Carlos Zarzar (1983):

Mientras mayor sea la relación que el alumno vea entre aquello que estudia y su vida (presente, pasada y/o 
futura) mayor será su empeño y dedicación al estudio y los aprendizajes que logre serán más profundos y duraderos. Esto solo será posible redefiniendo el papel del alumno en el proceso de enseñanza-aprendizaje, en el sistema de educación tradicional los alumnos desparecen como personas.

De Zubiría (1985) lo expone así:

[...] para asumir en el aula una equivocada presencia fantasmal, despersonalizada y sin interés. Con este proceder impersonal, el profesor ignora o pretende ignorar la riqueza y complejidad espiritual del estudiante, $y$ en vez de estimular, termina por represar su potencial y energías creativas. Así [...] con un solo interlocutor desaparece el dialogo, y con ello, las posibilidades de evolución espiritual del estudiante, condenado de este modo a ser un pasmado mental.

En oposición a esta tendencia, el educador debe situar al estudiante en el centro del acto educativo, por tanto, "en vez de preocuparse por la forma en que podrá enseñar algo, transmitir determinado conocimiento, debe preocuparse de qué manera será capaz de crear una relación y clima que el estudiante pueda utilizar para su propio desarrollo" (Rogers, 1975); solo así, tomando en cuenta la heterogeneidad del estudiante, reconociendo sus intereses, se pueden idear situaciones significativas y reales de aprendizaje.

Por otro lado, se sabe que entre los estudiantes existen desigualdades en torno al acceso a recursos de la cultura escrita, ya advertía Lasso Tiscareno que la mayoría de los niños y jóvenes no tienen libros ni revistas en su casa, ni existen condiciones de acceso a bibliotecas donde consultarlos. El profesor debe mostrar que para la investigación de los temas existen distintos medios con información relevante: libros, revistas, periódicos, Internet, etc.; un mismo contenido puede ser visto desde muchos ángulos, la finalidad es enseñar a visualizar más de uno y no satisfacerse solamente con lo primero que se encuentra. Monje Margeli, (1993) se expresa al respecto:

La clave está en enseñar a comprender y en buscar la comprensión. Lo que es el mundo y lo que pasa en el mundo. Lo que a los niños y los jóvenes especialmente les afecta, interesa y pueden comprender. $Y$ conocer lo que los libros, la prensa y otras manifestaciones escritas pueden aportar.

Además, enfocándonos meramente en el ámbito de la ortografía, aunque los contenidos que generan la motivación no sean académicos, la acción de leerlos será beneficiosa para la aprehensión del hábito, pues como señalan Gabarró y Puigarnau (1996): la lectura y la escritura siempre incrementan el vocabulario del lector, pero si, además, éste tiene incorporada de forma inconsciente el proceso ortográfico visual, aumentarán también su vocabulario ortográfico personal, y añaden:

[...] se aprende igual leyendo una revista que un libro, leyendo por placer que por estudio, en la clase o en la piscina... Naturalmente hay diferencias literarias importantes entre García Márquez y una revista del corazón, pero estas diferencias son inexistentes a nivel del hábito de la lectura.

Segunda Consigna. Fomentar realmente la elaboración de textos libres. Al igual que en la lectura, las actividades de escritu- 
ra ya están definidas en los libros de texto, las cuales generalmente se enfocan en averiguar aprendizajes previos, reforzar conocimientos o como herramientas al servicio de la calificación, aunque erróneamente se crea que es evaluación. El libro de texto para secundaria "Español 1: Comunico lo que siento", por ejemplo, presume en su prólogo promover el desarrollo de las capacidades orales y escritas de los alumnos, despertar una actitud analítica y reflexiva, y acercarlos de manera amigable al fascinante mundo de la literatura.

Todos estos objetivos se esperan alcanzar mediante la generación de proyectos, sin embargo, siendo críticos, éstos no terminan siendo otra cosa que las tareas de producción escrita de siempre: investigación y transcripción de mitos y leyendas, resúmenes de monografías, elaboración de cuentos, cartas e informes de ciencias, exposición y creación de líricas nacionales, etc.; a pesar de mostrar un cambio respecto a la metodología de antaño, el objetivo perseguido sigue siendo el mismo: reproducción de conocimiento y aprobación de tareas.

Estas tareas priorizan la posesión de un "discurso sobre la realidad" y el saber hacer, aunque carezcan de resonancia interna para el sujeto, en esta circunstancias "la maestra y el maestro, en su papel de educadores, se conformarán con la expresión de un discurso sobre las cosas, sin necesidad de confrontar el enunciado de esa verbalización con una experiencia vivencial de aprendizaje" (Blanco Beledo, 1982).

En otras palabras, la práctica de lectura y redacción en la escuela ya están estable- cidas a un tipo de composición en particular (resumen, paráfrasis, exposición, ideas centrales, etc.) y a un tema específico (la célula, la independencia de México, la historia del baloncesto, la invención de la imprenta, etc.), por tal motivo, regularmente los estudiantes no encuentran un interés verdadero en estas experiencias de aprendizaje que vaya más allá de aprobar la tarea, pues los ejercicios se asimilan como instrucciones que indican qué producir (tipo de composición), cómo llegar al producto deseado (estructura de la composición), a quién será dirigido (el profesor) y con qué fin (aprobar la tarea). Incluso cuando alguna actividad presume "escritura libre", ésta no lo es tanto, ya que si están en el tema de la lírica nacional y se pide a los estudiantes formular una con temática a elegir, el contenido es libre en efecto, pero no así el producto.

Para Isabel Álvarez (2009) la producción de textos "es un proceso cognitivo complejo mediante el cual la persona traduce sus representaciones mentales, ideas, pensamientos, sentimientos e impresiones en un discurso escrito coherente, en función de hacérselos llegar a una audiencia de una manera comprensible y para el logro de determinados objetivos", no obstante, la redacción planificada de la escuela despoja a la escritura de toda creatividad, simplifica este complicado proceso cognitivo a una tarea casi mecánica que no exige plantear qué escribir, con qué objetivos, para quién y cómo escoger las palabras adecuadas para elaborar un discurso propio. Quizá este tipo de prácticas propicien que los estudiantes conciban la escritura a niveles ejecutivo y funcional, sin mostrar 
que ésta puede usarse para recrear y hasta para transformar el conocimiento.

Ahora bien, en la adolescencia los jóvenes sienten la necesidad de expresarse, de tal forma que, es sabido, tienen mucha más capacidad para producir textos, inventar historias o imaginar escenarios, incluso lo encuentran más productivo e interesante que el simple hecho de completar tareas, pero la escuela raramente permite la expresión libre, por ello la escritura es voluntaria y significativa en Internet, porque ahí los jóvenes tienen la libertad de leer y escribir géneros discursivos propios, valiéndose así de procedimientos particulares que mezclan el comentario, la crítica, las citas, la opinión, etc. Se necesita transportar esas prácticas a la hoja en blanco que yace en el pupitre, hacer a los estudiantes partícipes igualando la libertad de los espacios virtuales. ¿Cómo se puede llegar a esto?

A través del texto libre. Complementario a la lectura centrada en aficiones -sugerida en el primer punto-, se puede pedir a los estudiantes registrar de forma manuscrita, la conclusión alcanzada después de haber revisado otros materiales relacionados al tema principal, sin importar en el producto final la extensión, temática o el género discursivo (crítica, opinión, resumen, impresiones, etc.). Es decir, explotar mediante la escritura los deseos de conocer y de expresarse típicos de la adolescencia, pero situados en un ambiente libre de presión, donde los textos producidos sean sencillos pero propios y significativos, de esta forma se espera recuperar la esencia creativa de la producción escrita, ponerla al servicio del estudiante y no al revés, tal como lo proponen los espacios virtuales.
Se podría objetar fácilmente que el texto libre es un recurso que debe usarse con cautela, pues tiende a caer cómodamente en el desorden o en escritos irrelevantes, sin embargo, al igual que la lectura basada en intereses, no se pretende desarrollar el tema electo como principal objetivo, sino mostrar que la escritura es un acto de reelaboración de ideas y de relación con los demás, la cual está al servicio del escritor para hacer llevar a otros la visión propia del mundo.

Tercera Consigna. Problematizar las situaciones de la lectura y la escritura. Los dos puntos anteriores serían poco eficaces si no se plantean las actividades de redacción como situaciones a resolver, esto es, la escuela actualmente problematiza las tareas de composición, pero lo hace de tal forma que solo exista un camino para llegar al producto, como si se tratase de un ejercicio de matemáticas; el quid es problematizar la escritura pero como un escenario "mal definido" en el que no exista una única vía de solución, ni una única solución posible. El texto libre es el perfecto ejemplo de este planteamiento, ya que para "resolverlo" se puede valer de una vastedad de procedimientos que a su vez pueden originar una diversidad de productos finales, todos ellos aceptables en términos de respuesta al problema.

Para diversos autores, las tareas de producción escrita pueden afrontarse desde dos modelos principales de resolución: el primero, denominado "decir el conocimiento", presume llegar a la composición de textos sin un plan establecido, donde los ejes cardinales giran en torno al contenido y el tipo de género discursivo; básicamen- 
te, éste consiste en buscar en la memoria algún elemento que sea pertinente en la relación a la tarea asignada y que permita empezar a elaborar el texto.

Una vez encontrado este elemento, el escritor produce una primera porción de texto, que utiliza para generar nuevos identificadores de tópico y de género y reiniciar de este modo la búsqueda en memoria de un nuevo contenido. Este proceso de produce una y otra vez, hasta que el escritor ya no es capaz de encontrar más ideas, o simplemente decide dar por finalizado el texto (Miras, 2000). El segundo modelo, referido como "transformar el conocimiento", parte, similar al anterior, del tema y el producto que se espera generar, pero se analiza la tarea y se fijan objetivos concretos que definirán la composición; la estrategia de éste esencialmente postula que al examinar la tarea, el escritor se plantea qué decir, con qué intención, cómo decirlo y para quién, y en la medida en que estas incógnitas son resueltas el texto se construye, alcanzando incluso la reestructuración del conocimiento original que el escritor tenía sobre el tema.

Ambos modelos corresponden a estrategias para abordar el problema de la redacción, válidos en términos de respuesta a la tarea, pero distintos en sus funciones. Claramente en la técnica "decir el conocimiento", empleada predominantemente en las aulas, el escritor plasma el conocimiento que ya posee, lo que no supone un reto a nivel cognitivo, llevando la escritura a un nivel instrumental; mientras que "transformar el conocimiento" implica escribir reflexivamente: organizar las ideas con base en objetivos, planificar coherentemente los argumentos para sensibilizar al lector, ex- plicitar al máximo la visión personal del contenido a fin de reducir la distancia entre el escritor y el destinatario, escoger las palabras adecuadas, $y$-si es posible- modificar su conocimiento durante el proceso.

El desarrollo de esta estrategia supone suscitar la función epistémica de la escritura, la cual, complementando lo que ya se había plateado con G. Wells, concretamente puede entenderse como el aprendizaje que los escritores experimentan durante el proceso de composición de un texto, implicando no solo la afinación y organización de los conocimientos del contenido y las estructuras discursivas, sino también la transformación de esos conocimientos, en otras palabras, "[...] el escritor que utiliza esta estrategia de escritura, no sólo aprende acerca de lo que se escribe, sino que también aprende a escribir" (Miras, 2000).

La elección de alguna de estas dos estrategias está relacionada con el nivel de conocimiento que se tiene sobre el tema a desarrollar, si el escritor cuenta con escasa información y no está motivado para investigar (sea quizá porque el tema no le interesa, como los ejercicios propuestos en la escuela), se inclinará más hacia el modelo "decir el conocimiento", es decir, "exponer" lo poco que sabe; pero, si por el contrario se cuenta con recursos variados y el tema es significativo, la posibilidad de suscitar el proceso de "transformar el conocimiento" es amplia.

Resumiendo, si bien es cierto que algunos géneros discursivos estimulan la función epistémica de la escritura, ésta no es exclusiva de una estructura en particular. Se comentó líneas arriba que el texto libre 
es un excelente arquetipo, pues da pautas para problematizar la redacción como una situación "mal definida", pero este recurso fácilmente caería en la función instrumental si el profesor a cargo no lo presenta como un material libre en el cual se expone algo, con determinados fines, a ciertos lectores y con una infinidad de alternativas.

Para que estos ejercicios sean provechosos, el profesor debe sugerir (sin imponer) ciertas interrogantes que los estudiantes deberán pensar antes y durante la tarea, la resolución a éstas ayudaría en la elaboración y estructuración del contenido, dichas cuestiones implican plantear: ¿Cuál es el fin de la composición: defender el tema o dudar de él? ¿Cómo se expondrán los argumentos (cifras, citas, opiniones, reseñas, impresiones, etc.)? ¿En qué elementos me baso para esos argumentos (fuentes de consulta)? ¿Quiénes apoyan o desaprueban mi perspectiva? ¿Para quién será dirigido el escrito: público familiarizado al tema o público en general? En relación a esta última cuestión, los expertos recomiendan, para hacer más rica la reflexión, que las composiciones sean dirigidas a un público no experto, eso obliga a los escritores a replantear la organización de los argumentos y explicitar minuciosamente el contenido.

Cuarta Consigna. Repensar la estrategia de corrección de los textos. En diversas ocasiones los profesores asumen la ortografía como un elemento central a tomar en cuenta para la valoración de un escrito, pero la utilizan como un componente meramente punitivo. Reprender a un estudiante por su ortografía, lejos de servir como experiencia de aprendizaje, aviva el miedo a escribir y despierta la inseguridad para explorar y emplear nuevos términos.

Para que la ortografía deje de ser algo abrumador y no frene el interés y la ganas de escribir, se debe exponer como una herramienta que da brillo a las creaciones escritas, es decir, que su función es la comprensión discursiva y no solo para satisfacer las demandas de un profesor estricto.

Volvamos a lo que ya se ha sugerido: separar la ortografía de la escritura o, peor aún, tomarla como un instrumento sancionador, la hace parecer un elemento con escasa utilidad que sólo existe para hacer difícil la tarea de componer. De acuerdo a diversos manuales de redacción para profesores, la ortografía debe fomentarse en la escuela, pero sin remarcar su estudio; una opción para trabajarla, sin colocarla en el centro del aprendizaje ni precisarla como elemento de evaluación, podría encontrarse si se asume ésta como un objetivo notemático; según Zarzar (1983) los objetivos de aprendizaje de un curso pueden dividirse en dos tipos: objetivos temáticos y objetivos no-temáticos.

Los objetivos temáticos corresponden a los aprendizajes esperados alrededor de la temática propia de una asignatura, van incluidos expresamente en el programa de la misma y se espera conseguirlos y agotarlos durante el curso en cuestión; los objetivos no-temáticos, por su parte, implican aquellos aprendizajes (o modificaciones de pautas de conducta) no relacionados directamente con la temática establecida, no están necesariamente incluidos en el programa y por ello no se esperan alcanzar en su totalidad durante el tiempo que dure el cur- 
so, a diferencia de los objetivos temáticos, los cuales se consiguen prioritariamente por el contenido mismo, los objetivos notemáticos se cumplen a través de la manera en cómo se desarrollan esos contenidos. $\mathrm{Si}$ la enseñanza/recuperación de la ortografía se asimilara en las asignaturas como un elemento fuera de las temáticas y objetivos preestablecidos, habría oportunidades más flexibles para trabajar con ella, lejos de la presión que representa dominar los objetivos concretos, situándola en un segundo plano al servicio de la escritura.

Por otro lado, si se pretende fomentar en los estudiantes la cultura escrita y hacerlos partícipes en las tareas de composición, las producciones libres que elaboren deben valorarse por el contenido, la creatividad de los argumentos, y los objetivos alcanzados (qué decir, cómo decirlo, para quién, con qué fin) y no situar en el centro la ortografía, el profesor puede hacer sugerencias en este campo, pero sin sancionar, es decir, leerlas sin "conciencia ortográfica (Gabarró y Puigarnau, 1996).

Podría parecer un tanto contradictorio que esta investigación verse sobre los errores en las grafías y se exponga, a su vez, que exista cierta permisividad al examinar los escritos, pero antes que la ortografía está el objeto al que sirve: la escritura. Si se proporciona a los estudiantes la confianza para elaborar textos propios, significativos y reflexivos, tarde o temprano la correcta escritura se asimilará como una herramienta que aporta comprensión y belleza al discurso. Es tal como sugiere Cassany (2012) "[...] al inicio hay que dar confianza para escribir, para comunicarse por escrito $y$, más adelante y poco a poco, los aprendices irán comprendiendo la importancia de la corrección, como mejora de la calidad de los textos que escriben y como una profundización en el conocimiento del sistema de la lengua".

Quinta Consigna. Redimensionar el papel de la evaluación. Como se insinuó en apartados recientes, las tareas de redacción y composición que propone la escuela están directamente ligadas con la evaluación, la cual, la mayoría de las veces, consiste en verificar la respuesta "correcta" o la ejecución del procedimiento formulado en el libro de texto (los tipos de géneros discursivos en este caso) a fin de conceder una calificación; esta noción sumativa y/o acumulativa de la evaluación, pero que en realidad es medición, es donde lo importante es asignarle un número o una nota a lo que se está trabajando, condiciona el aprendizaje y las acciones de los estudiantes (y el profesor) ya que, lejos de ser una herramienta verdadera que auxilie a la reflexión en el proceso de enseñanza, centra el interés en aprobar ejercicios, verificar resultados y acumular notas. En otros escritos he mencionado que la evaluación:

Es uno de los más graves efectos de esta concepción francamente negativa de la evaluación se da en la formación misma del estudiante: hace recaer su atención en la forma de aprobar los exámenes y no en el esfuerzo de aprender, enfatiza el valor de la calificación y no en el sentido mismo del conocimiento; además hace que la evaluación se dé casi siempre en condiciones especiales de preocupación, miedo y tensión, con lo cual se distorsiona el sentido intrínseco no 
sólo de la evaluación sino de la educación misma (Morán, 2012).

Sería inaplicable sugerir modificar estas arraigadas prácticas en la educación básica (aunque es lo ideal), no obstante, al plantear estas pequeñas experiencias de escritura como ejercicios "complementarios" o anexos al plan de estudios formal, es posible prescindir de la evaluación convencional. Esto se idea ya que, sin la intención de explorar los diferentes matices que convergen en torno al tema, diversos especialistas en educación critican severamente el sistema de calificación en las aulas, pues, a pesar de los importantes cambios metodológicos que se han suscitado durante la última década, el discurso y la intención de aprovechar la evaluación en diferentes niveles (diagnóstica, de avances, final y tipo PISA) se establece como un proyecto que los docentes deben desarrollar a lo largo de cada unidad temática, más la realidad dictamina que al final ésta se ejecuta tradicionalmente, no da la oportunidad de revisar el proceso de aprendizaje ni ayuda al estudiante en las dificultades identificadas, sólo importa elaborar evidencias que verifiquen el dominio de los contenidos y la presencia de las habilidades estipuladas en los objetivos, registros que al término de cada bloque son valorados completamente al criterio "inequívoco" del profesor.

En palabras más simples, se tiende a adiestrar a los estudiantes para conseguir la nota aprobatoria como meta central, dejando en segundo plano el aprendizaje; por ende, los escritos producidos generalmente sirven como medio para engrosar carpetas, como "evidencias" o registros de la exploración del tema, pero está en duda si se facilita un acercamiento real a la cultura escrita, así como la formación de lectores y escritores reflexivos, ya que esencialmente el único objetivo consiste en entregar y aprobar avances. El alumno ante este panorama, recibe información, acumula teoría, pasa exámenes, acredita materias, pero no es capaz de usar crítica y pertinentemente dicha teoría, tampoco de pensar por sí mismo y de tomar posición frente a la realidad $\mathrm{y}$ al propio conocimiento.

El estudiante es una persona que cree aprender, porque acumula saberes, emite respuestas, obtiene notas y acredita materias - noción convencional de evaluación- pero sin comprender qué aprende, cómo aprende y para qué aprende.

Por lo consiguiente, si el fin de estos puntos es diseñar estrategias didácticas que promuevan situaciones de producción escrita donde no hay una única respuesta, la evaluación que conocemos resulta incompatible; en consonancia, la valoración de los textos elaborados en estas circunstancias no pueden llevar una calificación, más que el simple acto de otorgar un número representativo, en cambio, si se fomenta el cultivo de la subjetividad, el ejercicio de tareas cualitativas, el lector puede ofrecer su opinión personal fundamentada respecto al texto, así como sugerir la afinación de ciertos elementos.

Desde luego podría darse la cómoda situación en donde la revisión del destinatario sea poco provechosa o caiga en comentarios simples y monosilábicos que expresen conformidad o discrepancia en relación al contenido, por tal motivo se pueden recomendar ciertas preguntas que 
el lector debería plantearse al término de la lectura, tales como: ¿Qué estuvo bien? ¿Qué estuvo mal? ¿Qué faltó? ¿En qué se puede mejorar?

La resolución a estas incógnitas exige a quien lee emplear su criterio por encima de lo habitual con la finalidad de proporcionar al autor sugerencias que le ayuden a redactar mejor; se espera que esta valoración de los escritos sirva de verdad en el acto educativo y deje de entenderse como una actividad concluyente, así la evaluación, visualizada de esta manera, no es un momento final, sino un periodo de reflexión y reconstrucción que abre el camino a otros procesos donde el evaluado puede asimilar las pautas, confrontarlas, rechazarlas, negociarlas, etc. Esta noción de evaluación se apoya sustantivamente en el siguiente planteamiento:

La evaluación puede concebirse y utilizarse también como una actividad destinada a propiciar el aprendizaje, a su regulación y no solamente a la comprobación de la adquisición del mismo. No es el momento final de un proceso y, aunque así se viva frecuentemente, es en esencia la conciencia vigilante de dicho proceso, dada su relevancia debiera convertirse en el comienzo de un nuevo proceso, más profundo, recuperando así su sentido de retroalimentación (Morán, 2007).

La concepción de este punto le guiña el ojo una vez más a los espacios virtuales, ese lugar en el que los usuarios escriben y son retroalimentados por lectores voluntarios, donde la valoración de los escritos -en sus diferentes variedades- no se realiza mediante una escala numérica, sino a través de una retroalimentación compartida, au- tónoma, en tiempo real y auténtica, que, en diversas ocasiones, proporciona elementos para reflexionar sobre lo comunicado.

Sexta Consigna. Cassany y Hernández describen: Cómo los textos producidos en Internet son retroalimentados por "comunidades auténticas", donde la interacción gira alrededor de componentes emocionales y personales. Sería complicado tratar de reproducir ese público genuino en el aula, no obstante, se podría llegar a una aproximación si el profesor legara el proceso de valoración a los alumnos, esto es, podrían tomarse las composiciones del grupo y repartirlas aleatoriamente entre ellos mismos o en su defecto dotar a éstos con la libertad de intercambiar sus producciones a voluntad, cualquiera de las dos opciones intenta semejar la realimentación suscitada en el ciberespacio, puesto que rompe el esquema de "escribir para el profesor", así los aprendices saben que no están redactando ya para una persona en específico, sino que lo hacen para un igual.

Este objetivo será alcanzable si el docente se considera a sí mismo un coordinador o propiciador, en lugar de asumirse como el actor principal del proceso enseñanzaaprendizaje, ya que, como sugiere Carlos Zarzar, en algunos casos los alumnos no se esfuerzan tanto por aprender sino por agradar al profesor, haciendo lo que él quiere que hagan, respondiendo a lo que él quiere que respondan, actuando como él quiere que actúen. Los puntos sugeridos en estas páginas requieren un profesor-coordinador, alguien que guie las actividades de aprendizaje, despierte y maneje las potencialidades del grupo $y$, sobre todo, que 
sitúe en el centro de todo el acto educativo al estudiante, así el docente se ubica a una distancia óptima, tanto del grupo como de la tarea, que le facilite observar al grupo, la dinámica de éste, su proceso de organización y trabajo en función de los aprendizajes. A través de esta observación, podrá ir captando la dinámica del grupo y podrá ir orientando o re-orientando las actividades propias del curso.

Con un docente propiciador se rompe la tradicional concepción de "llenar" a los alumnos de conocimientos, pues no se trata de "transmitir" información, sino de construirla a través del descubrimiento y la experiencia compartida. Al respecto dice Marta Pasut (1993): "el profesor se convierte ahora en un coordinador asumiendo un liderazgo más vital, movilizando situaciones de comunicación, organizando experiencias de aprendizaje, diseñando nuevos escenarios, guiando la evaluación", y añade:

[...] está en la búsqueda constante y planifica la tarea, la encuadra, elige las técnicas adecuadas, con las que trabajará cada contenido para hacer realidad las potencialidades del grupo, observa y evalúa procesos individuales y grupales [...] éste se convierte en un guía, un orientador que conoce en profundidad el contenido que el alumno desconoce y hará todo lo posible para que ellos vayan descubriéndolos por sí mismos, porque su actitud difiere totalmente de la del profesor tradicional, es decir, solucionador.

En este mismo tenor, compartir la evaluación a los estudiantes resulta más enriquecedor y provechoso que el modelo habitual profesor-alumno, incorporando el vínculo alumno-alumno, esto es, la moda- lidad de la coevaluación, la que involucra a los estudiantes en el proceso valorativo de los escritos, de las tareas, los hace partícipes del momento que tradicionalmente se le confiere al profesor, y se convierte en una situación más de aprendizaje en la cual evaluador y evaluado aprenden del rol asignado, el primero ejercita su juicio particular y el posicionamiento personal frente a los argumentos del escritor, el segundo, por su parte, aprende a escribir para un público desconocido y a confrontar la crítica y sugerencias del mismo. Con relación a este punto, se expone lo siguiente:

En nuestro medio parece estar instalado el concepto de evaluación como amenaza, como castigo, solo cuando la evaluación es una tarea compartida, colectiva de todos los involucrados en la tarea educativa se le quita esa connotación de persecución, o ajuste de cuentas; se necesita comentarla, discutirla con los interesados (los que la gozan o los que la padecen) con los que están inmersos en el proyecto y proceso educativo, sólo así se gana credibilidad y equidad en el acto evaluativo (Morán, 2007).

Es importante concebir al acto educativo con la heterogeneidad de sus individuos $\mathrm{y}$ en sus relaciones como grupo, en este sentido la coevaluación es un elemento más, pero muy importante, que ofrece a los estudiantes la oportunidad de relacionarse con el otro, adentrándose a perspectivas diferentes donde se aprende que el conocimiento no es algo acabado, porque siempre puede verse desde otro ángulo. Sobre este punto Rafael Santoyo comenta:

La interacción, en situaciones de docencia, no es una relación de sujetos aislados sino más bien una relación 
de grupo y, en este sentido, de interacción múltiple. La interacción y el grupo son medio y fuente de experiencias para el sujeto. Es precisamente a través de y por sus experiencias que la persona aprende y se desarrolla como tal.

En suma, como simple acotación, es aconsejable que la extensión de las producciones escritas sean breves para no hacer agotadora la tarea de redactar y leer, quizá sin un mínimo de líneas establecido, pero sí con una extensión máxima, se trata también de que estas situaciones de aprendizaje pongan en práctica la selección de información relevante y muestre a los estudiantes que la calidad de un contenido no está ligada a su longitud. Así mismo, estas tareas extraescolares deberán ser elaboradas a mano para evitar la intromisión de software autocorrector de texto, común en programas como Microsoft Word, que podría interferir en la ejercitación de la ortografía y el desarrollo de la memoria muscular.

En cuanto a la regularidad de aplicación, no hay una estimación concreta, dependerá del criterio del docente, de las condiciones del curso, solo se debe tomar en cuenta el no abusar de estos recursos, pues su ejecución constante e insistente podría volverlos rutinarios. Dicho de otra manera, aquí está en juego la preparación y la creatividad del profesor.

Asimismo, es conveniente asentar lo siguiente: los puntos apenas esbozados no representan un modelo definido a seguir o una estrategia exhaustiva, la intención de estas pautas y reflexiones se enfocan a ofrecer una alternativa posible y deseable en el aula basada en sencillos planteamientos, los cuales pueden aprovecharse individualmente o en conjunto, lo idóneo es la aplicación conjunta, más la asimilación de estas sugerencias queda al criterio de los lectores potenciales -docentes- quienes pueden aprovechar libremente aquellas sugerencias que se adapten mejor a su estilo de docencia y a sus circunstancias académicas particulares.

Finalmente, habría que decir que promover la lectura y escritura en serio y, por medio de ellas ayudar a los niños, a los jóvenes y a los adultos a avanzar en su educación, en su actualización y en su superación implica, entre otras cosas, conocer las operaciones mentales que suscita un texto y estimularlos a leer y escribir hasta fomentarles el gusto, forjarles el hábito es la mejor costumbre en su vida.

Mal podemos enfrentar los retos de las nuevas sociedades de conocimiento con nuestra inmensa población iletrada, ajena a los libros y distante de su provocación intelectual. Mal vamos si, además, la televisión que ofrecen los consorcios que la ostentan se empeñan en reducir a la población a la condición de deficientes irredimibles.

Una política nacional de alfabetización como la que recurrentemente implanta el gobierno federal no puede limitarse a abatir el analfabetismo; debiera proponerse estimular a todas las personas a leer inteligentemente, desarrollando las habilidades intelectuales y afectivas que reclaman los diversos textos. Y esto supone contar con evaluaciones precisas y sistemáticas y dejar de refugiarnos en "supuestos" discutibles como el de que cuatro grados de primaria 
incorporan a una plena y permanente alfabetización. Leer y escribir -también en esta era de informática- siguen siendo los medios principales para aprender a pensar.

\section{Bibliografía}

Álvarez, I. (2009). Escritura creativa: aplicación de las técnicas de Gianni Rodari. En:www.scielo.org.ve/ scielo.php?script=sci_arttext $\&$ pid=S1316...

Blanco, R. (1982). ¿Dónde estamos? Docencia universitaria y desarrollo humano. Alhambra Mexicana. México.

Carrasco, A., Comp. (1988). El lenguaje en la escuela. [Unidad I] Antología. UPN. México.

Cassany, D. y Hernández, D. (2012). “internet: 1; Escuela: 0?”. Revista de Investigación Educativa Núm. 14, en: CPU-e, Universidad Veracruzana. México.

Castilla, C. (2001). La incomunicación. Editorial Península. Barcelona. España.

Chartier A.M., y HéBRARD, J. (2000). Saber leer y escribir: unas herramientas mentales que tienen su historia. Infancia y aprendizaje Núm. 89. París.

Freire, P. (1976). Pedagogía del oprimido. Siglo XXI Editores. Colombia.

Delval, J. (1977) El desarrollo humano. Siglo XXI: México.

Ferreiro, E. (1989). Los sistemas de escritura en el desarrollo del niño. Siglo XXI: México.

Gabarró, D. y Puigarnau, C. (1996). Nuevas estrategias para la enseñanza de la ortografía. Ediciones Aljibe: Málaga.

Gómez Palacio, M. (comp.). (1984). Nuevas perspectivas sobre los procesos de lectura y escritura. Siglo XXI: México.

LAsso, R. (2004). La importancia de la lectura. Universidad Autónoma de Ciudad Juárez. México.

Latapí, P. (2003). Cómo educar sin pedagogía, en: Horizontes de la Educación. Lecturas para maestros, Volumen I. Aula XXI. Santillana: México.

López, G. y Ciuffoli, C. (2012). Facebook es el mensaje. La Crujía: Buenos Aires.

Malvido, A. (1990). Por la vereda digital. Consejo Nacional de la Cultura y las Artes. México.

Monje Margeli, P. (1993). La lectura y la escritura en la escuela. Manual del lector y del escritor moderno. Editorial Renacimiento: Sevilla, España.

Morán, P. (2005). Consideraciones teórico-metodológicas de la instrumentación didáctica. Segundo En- cuentro Internacional sobre Didáctica Universitaria. Universidad Nacional de Loja. Ecuador.

Morán, P. (2010). Aproximaciones teórico-metodológicas en torno al uso del portafolio como estrategia de evaluación del alumno en la práctica docente. Experiencia en un curso de Laboratorio de Didáctica en la docencia universitaria. Perfiles Educativos Núm. 129, UNAM, México.

Morán, P. (2007). Hacia una evaluación cualitativa en el aula. Revista Reencuentro. Análisis de Problemas Universitarios Núm. 48. UAM-Xochimilco. México.

Morán, P. (2012). La evaluación cualitativa en los procesos y prácticas del trabajo en el aula. Colección Educación. IISUE, UNAM. México.

Ong, W. (1982). Oralidad y escritura. Tecnologías de la palabra. Fondo de Cultura Económica: México.

PAge, J. (1993). Hombre crítico u hombre implemento. Sección: Ideas. Periódico: La Jornada Semanal. Nueva Época, No. 201. México.

Pasut, M. (1993). Acerca del taller. El aula un taller, en: Viviendo la literatura. Editorial Aique. Buenos Aires.

PÉrez TAPIA, M. T. (2008). La reescritura como método para aprender a escribir: ortografía y ortotipografía. Universidad de Alcalá, Servicio de publicaciones: Madrid.

Porter, L. (1996). Educación y Creatividad. Revista Reencuentro: Análisis de Problemas Universitarios, Núm. 17. UAM-Xochimilco: México.

SAntoyo, R. (1985). Apuntes para una didáctica grupal. Ediciones El Caballito y SEP-Cultura: México.

SAViani, D. (1994). Sobre la naturaleza y especificidad de la educación, en: Pedagogía histórico-crítica. Primeras aproximaciones. Universidad de Campinas. Sao Paulo, Brasil.

URIBE, D. (1973). Didáctica de la lectura-escritura. Editorial Oasis: México.

Rodríguez, A. (1976). El proceso de aprendizaje en la educación superior. Colección Pedagógica Universitaria. Centro de Estudios Educativos de la Universidad Veracruzana. No. 2.

Rogers, C. (1975). Libertad y creatividad en la educación. Editorial Paidós: Buenos Aires.

Steiman, J. (2004). Lectura y vida. Tipos de enseñanza específica, más allá de la presentación oral de la clase. Ediciones Espartaco. Montevideo, Uruguay.

Tascon, M. y ABAD, M. (2011). Twittergrafía: El arte de la nueva escritura. Catarata: Madrid, España.

ZARZAR, C. (1983). Diseño de estrategias para el aprendizaje grupal. Una experiencia de trabajo. Perfiles Educativos Núm. 1, Segunda Época. CISE. UNAM: México. 